73rd Conference of the Italian Thermal Machines Engineering Association (ATI 2018), 12-14 September 2018, Pisa, Italy

\title{
Low-enthalpy geothermal systems for air conditioning: a case study in the Mediterranean climate
}

\author{
Caterina Frau ${ }^{\mathrm{a}}$, Enrico Maggio ${ }^{\mathrm{a}}$, Francesca Poggi ${ }^{\mathrm{a}}$, Emanuela Melis ${ }^{\mathrm{b} *}$, Francesco Floris ${ }^{\mathrm{b}}$, \\ Pier Francesco Orrù ${ }^{b}$ \\ ${ }^{a}$ Sotacarbo S.p.A., Grande Miniera di Serbariu, Carbonia, 09013, Italy \\ ${ }^{b}$ Department of Mechanical, Chemical and Materials Engineering of the University of Cagliari, via Marengo 2, Cagliari, 09123, Italy
}

\begin{abstract}
This paper presents a preliminary evaluation of the technical and economic feasibility of a low-enthalpy geothermal system for air conditioning and its integration with other systems, including a photovoltaic plant and an electrical storage system. The pilot building is a research center located in the southern side of the Mediterranean basin (Sardinia, Italy). Preliminarily, the main geological, hydrogeological and geothermal characteristics of the area were analyzed. Then, an energetic assessment of the building and its plants was performed. The hourly production of a photovoltaic plant already designed for the building was assessed. To improve the energy efficiency and the thermal energy self-consumption, an alternative thermal generation plant was proposed to replace the existing air conditioning system: a water-water heat pump coupled with a low-enthalpy geothermal probe (vertical configuration), to be embedded into the ground or placed into an existing groundwater well. The feasibility of electric storage was evaluated by considering a system capacity of $100 \mathrm{kWh}$ to temporarily store and self-consume the electricity overproduced by the photovoltaic plant. A preliminary economic assessment showed the viability of the photovoltaic system. The $100 \mathrm{kWh}$-capacity electric storage will increase the self-production percentage, but it is not economically affordable. The replacement of the current air-water heat pumps with one water-water heat pump will be economically convenient if coupled with a groundwater geothermal probe, but the solution of a vertical probe embedded into the ground is unsustainable, due to high drilling costs.
\end{abstract}

(C) 2018 The Authors. Published by Elsevier Ltd.

This is an open access article under the CC BY-NC-ND license (https://creativecommons.org/licenses/by-nc-nd/4.0/)

Selection and peer-review under responsibility of the scientific committee of the 73rd Conference of the Italian Thermal Machines Engineering Association (ATI 2018).

\footnotetext{
* Corresponding author. Tel.: +39 0706755725

E-mail address: emymelis@unica.it
} 
Keywords: electric storage; low-enthalpy geothermal energy; photovoltaic system; heat pump

\section{Introduction}

General framework - The aim of this study was to provide a preliminary assessment of the technical and economic viability of thermal energy production for heating and cooling, using a low-enthalpy geothermal system in the Mediterranean climate. It will consist of a water-water heat pump coupled with a vertical probe embedded into the ground or installed in an already existing groundwater well. This solution will be combined with other technologies (photovoltaic plant and electric storage made of batteries and/or electric vehicles), to increase the energy performance of a pilot building located in the Sardinian Island (the South of Italy). Based on the conceptual development operated at an international level (e.g. Norwegian ZEB Centre "Research Centre on Zero Emission Buildings") related to NZEB (nearly-zero emission building) and ZEB (zero emission building) buildings, the model proposed in this paper will allow the pilot building to become a ZEB-O-EQ or ZEB-O type [1]. For these categories of buildings, it will be possible to reach a compensation by self-producing energy through renewable sources (e.g. photovoltaic, geothermal, etc.), by excluding compensation of the embodied emissions (related to the life cycle of materials used, of construction techniques, and of materials transportation). In existing buildings, particularly the old ones, the achievement of further ambition levels in the ZEB hierarchy is very complex and can require high costs, not achievable in a short-to-medium therm. Thus, developing a model including a renewable source such as that of the low-enthalpy geothermal energy, will lead to a more efficient and effective management of energy demand and supply and to a good amount of the energy self-produced/consumed. In addition, it will allow to meet national, European and global goals of energy saving, reduction of the emissions due to not renewable sources, and reduction of the sole consumption of energy purchased from the grid. The energetic awareness can be developed through actions focused on reaching the objectives fixed by the European Union in the Directive 2010/31/EU, which defined N-ZEB buildings. The main objectives are to achieve the N-ZEB category by 2019 for public buildings, and by 2020 for the new ones. Possible measures are energy demand reduction via energy efficiency solutions, thermal energy and electricity production through energy supply solutions balancing energy supply and demand of each building.

Brief overview of the main design methods of vertical geothermal systems - As reported by [2], current methods can be classified as simplified methods for small systems, analytical methods aimed at a preliminary design (this is the case study presented in this work) and numerical methods for detailed analysis and design of large systems. At a technical level, various Countries developed their own standards or guidelines. In Italy, an analytical procedure was developed as a technical standard [3]. In the United States, two analytical methods were proposed by two international associations: American Society of Heating, Refrigerating and Air Conditioning Engineers (ASHRAE) and International Ground Source Heat Pump Association (IGSHPA), and they were applied also in European Countries or used as a basis to create national standards. Regarding numerical models, they are based on finite differences/finite elements to assess the borehole domain and the ground/aquifer domain. Thus, a short-time window is considered to provide detailed solutions of the problem and design an optimized geothermal system. They can be used since the first stage of the geothermal probes field design, but they can be seen also as a second step after a preliminary design of the maximum size of geothermal systems. A high number of studies of geothermal heat exchangers and their performance are available in the literature (see for instance: [4]; [5]; [6]).

\section{Case study}

\subsection{Pilot site}

The pilot building, established in 1938, is the seat of Sotacarbo S.p.A., a research center located in Sardinia (Italy). The main activities are related to offices, laboratories and a workshop. The current service plants are Lighting (indoor/outdoor), Air conditioning (AC), Vacuum systems for laboratories, Waterworks, Domestic hot water, Sewage 
discharge system. The AC plant (Tab. 1) consists of two reversible heat pumps (air-water): the normal operation is of one heat pump; the second one will work only if required.

Table 1. Main characteristics of the current AC system

\begin{tabular}{llll}
\hline & Thermal power $[\mathrm{kW}]$ & Electric power $[\mathrm{kW}]$ & EER or COP \\
\hline Cooling $^{(1)}$ & 169,3 & 33,5 & 5,05 \\
Heating $^{(2)}$ & 187,1 & 40,2 & 4,65 \\
${ }^{(1)} \mathrm{T}_{\text {inlet }}=7\left[{ }^{\circ} \mathrm{C}\right]-\mathrm{T}_{\text {outdoor }}=35\left[{ }^{\circ} \mathrm{C}\right]$ & $(2)$ & $\mathrm{T}_{\text {inlet }}=45\left[{ }^{\circ} \mathrm{C}\right]-\mathrm{T}_{\text {outdoor }}=\left[7^{\circ} \mathrm{C}\right]$ \\
\hline
\end{tabular}

Monitoring system of electric consumption - Quarterly-hour data detected are (workshop is excluded):

- Electric cabin (total consumption of the research center)

- Laboratories (total consumption of this section)

- Offices (total consumption of this section; it includes also the auditorium)

- Standard office (an office was assumed as representative of the offices)

- $\mathrm{AC}$

Planned integration to the current configuration of plants: the photovoltaic plant - To enhance the energetic performance of the pilot building, a photovoltaic (PV) plant will be installed. The electricity production will be in parallel with respect to the national grid. This multisection PV plant will be made of 324 polycrystalline silicon panels, $270[\mathrm{~kW}]$ of nominal power each, and of 4 inverters. The most part of the energy produced will be self-consumed, the remaining part will be introduced into the grid. The total power is 87,48 [kW].

The Sotacarbo's groundwater well - An existing groundwater well is jacketed by using an iron tube (Ø 28). Inside it there is a polyvinyl chloride coating. The well depth is $110[\mathrm{~m}]$ circa and the pithead is 15 [cm] height. Already existing data on groundwater temperatures were considered to define the operative temperatures of the proposed geothermal system. In 2016-2017, water temperature measures were performed at few meters above the water free surface. Temperature is almost constant: between $24,3\left[{ }^{\circ} \mathrm{C}\right]$ and $24,4\left[{ }^{\circ} \mathrm{C}\right]$ in 2016 ; close to $25,5\left[{ }^{\circ} \mathrm{C}\right]$ in 2017 . No other pieces of information about the well are available.

\subsection{Methods}

Territorial framework of the pilot area - General geological, hydrogeological and geothermal features (based on the literature) were analyzed, to model the low-enthalpy geothermal system.

Energetic analysis -The steps followed for the energetic analysis are described below.

a. Energy consumption

Electricity consumption was evaluated using electricity bills on a monthly basis (period 2013-2016), electricity consumption data on a quarterly-hour basis (bills), and monitoring system data (quarterly-hour values). Based on electricity bills, electricity consumption was assessed. Quarterly-hour values of bills were added up together to obtain a single hourly value, to build the consumption profiles of an average working day and non-working day of each month. Specifically, for the working days of a month, hourly values have been averaged; the same was performed on the non-working days of a month. Then, the consumption profile on an hourly basis of each day of the year was obtained. The consumption values monitored through a detecting system were used to obtain consumption profiles of each zone. The workshop consumption was obtained by difference between total consumption and those of labs, offices, and AC. Data of the monitoring system were used to obtain consumption profiles on an hourly basis, for an average working day and an average non-working day of each month, for each monitored section. Comparisons were made between bills and cabin data and between monitoring system data and bills.

b. Energy performance evaluations

Energy performance indicators were estimated and compared to reference values (benchmark) [7]: annual electricity consumption per unit area $\left[\mathrm{kWh} \cdot \mathrm{m}^{-2}\right]$ and annual electricity consumption per employee $\left[\mathrm{kWh} \cdot\right.$ person $\left.^{-1}\right]$. 
Calculations considered the annual energy consumption by using bills and monitoring system data.

c. Hourly production profile of the PV plant

The hourly production profile of the PV plant during a solar year was obtained using a commercial software, which inputs are: site's characteristics and of the plant sections.

\section{d. Electric storage scenario}

The most of the energy produced by the PV plant will cover the energy demand. Potential temporary excess of the energy produced will be introduced into the grid. An electric storage can help reducing the mismatching between PV production and energy required by the user and increasing the energy self-produced and consumed. Firstly, the technical feasibility of an infinite-capacity storage system was evaluated. Then, a $100 \mathrm{kWh}$-capacity storage system was analysed, by comparing it to PV plant production and energy demand of the building.

e. Heat pump coupled with a low-enthalpy geothermal probe for heating and cooling

Technical specifications of water-water heat pumps combinable with geothermal probes available on the national market were compared, to select a performing model to meet the energy demand of the building and the operating conditions required. A unique heat pump will replace the two air-water heat pumps already installed (oversized). The current Italian standard to perform the dimensioning of geothermal probes is [3]. Due to the scarce availability of data and information related to case under consideration at the time of the study, a first evaluation of the probes length was performed by comparing three other methods:

- VDI 4640 method provided by the German regulations [8]

- The American Society of Heating, Refrigerating and Air-Conditioning Engineers (ASHRAE) method [9]

- The International Ground Source Heat Pump Association (IGSHPA) [10]

The first is a simplified method, valid for plants of thermal power less than $30 \mathrm{~kW}$ and only for heating. The second one is a complex method, requiring a big data set. Only some of those parameters were available for the study; thus, the third method was selected. The length of the probe $\mathrm{L}$ is the maximum value between the length for the cooling season and that for the heating season. The related equations are:

$$
\begin{aligned}
& \mathrm{L}_{\mathrm{h}}=\frac{\left(\operatorname{Capacity}_{\mathrm{h}} \frac{\left(\mathrm{COP}_{\mathrm{h}}-1\right)}{\operatorname{COP}_{\mathrm{h}}}\left(\mathrm{R}_{\mathrm{p}}+\mathrm{R}_{\mathrm{g}} * \text { RunFraction }_{\mathrm{h}}\right)\right)}{\left(\mathrm{T}_{\mathrm{g} \cdot \mathrm{min}, \mathrm{a}}-\mathrm{T}_{\mathrm{f}, \mathrm{min}}\right)} \\
& \mathrm{L}_{\mathrm{c}}=\frac{\left(\text { Capacity }_{\mathrm{c}} \frac{\left(\operatorname{COP}_{\mathrm{c}}-1\right)}{\operatorname{COP}_{\mathrm{c}}}\left(\mathrm{R}_{\mathrm{p}}+\mathrm{R}_{\mathrm{g}} * \text { RunFraction }_{\mathrm{c}}\right)\right)}{\left(\mathrm{T}_{\left.\mathrm{f}, \text { max }-\mathrm{T}_{\mathrm{g} \cdot \mathrm{max}, \mathrm{a}}\right)}\right.}
\end{aligned}
$$

where:

- Subscripts $\mathrm{c}, \mathrm{h}=$ cooling, heating

- $\mathrm{L}_{\mathrm{h}}, \mathrm{L}_{\mathrm{c}}=$ total length of the probes [m]

- Capacity $=$ Design power $[\mathrm{W}]$ of the plant

- $\mathrm{COP}=$ Coefficient of Performance (in the case of cooling, the COP is known as EER)

- RunFraction $=$ the factor used to partialize the monthly load (equivalent monthly hours/total hours per month), (in accordance with [11], from November 15 to March 31, for the heating process it is assumed that the operating hours per day are 10 for the climatic zone "C")

- $T_{g . m i n}, T_{g . m a x}=$ minimum and maximum temperatures of the ground in a year

- $\mathrm{T}_{\mathrm{f}, \min }, \mathrm{T}_{\mathrm{f}, \max }=$ minimum, maximum temperatures of the fluid into the geothermal probes in a year

- $\mathrm{R}_{\mathrm{p},} \mathrm{R}_{\mathrm{g}}=$ probe's resistance $\left[\mathrm{m} \cdot \mathrm{K} \cdot \mathrm{W}^{-1}\right]$ and ground resistance $\left[\mathrm{m} \cdot \mathrm{K} \cdot \mathrm{W}^{-1}\right]$

The iterations performed in accordance with the description provided by [12].

Electricity consumption data provided by the monitoring system of the AC plant were used. The periods June to September and November to March were considered for cooling and heating. By assuming an outlet temperature of 7 
$\left[{ }^{\circ} \mathrm{C}\right]$ for cooling and $45\left[{ }^{\circ} \mathrm{C}\right]$ for heating, COP and EER were, then, calculated. Starting by the hourly value of COP, thermal energy $[\mathrm{kWh}]$ exchanged with the building (heating) was calculated as COP multiplied with absorbed electricity [kWh]. Similarly, thermal energy exchanged with the building (cooling) was calculated by using EER values. Thus, hourly and monthly values of thermal energy exchanged with the building were obtained. It was assumed a N-probes field of double-U type and made of polyurethane tubes: 40 [mm] of diameter and 3,7 [mm] of thickness. To determine the total length of tubes, the Eqq. 1 and 2 were solved, by selecting the maximum length. Values assumed are listed in Tab. 2. Thermal diffusivity of the ground was fixed as $2,33^{*} 10^{-3}\left[\mathrm{~m}^{2} \cdot \mathrm{h}^{-1}\right]$ (in accordance with the geological framework of the study area, the soil type is related to fine to coarse sands) and its thermal conductivity as $1,5\left[\mathrm{~W} \cdot(\mathrm{m} \cdot \mathrm{K})^{-1}\right]$. The total length of tubes to meet the heating demand is $2714[\mathrm{~m}]$. To calculate the length in cooling conditions, the Eq. 2 was solved. The values assumed are listed in Tab. 2.

\begin{tabular}{|c|c|c|c|}
\hline Capacity $_{\mathrm{h}}{ }^{\mathrm{a}}$ & $187,4 * 10^{3}[\mathrm{~W}]$ & Capacity $^{\text {a }}$ & $203,25 * 10^{3}[\mathrm{~W}]$ \\
\hline $\mathrm{COP}^{\mathrm{a}}$ & 5,9 & $\mathrm{COP}^{\mathrm{a}}$ & 6,7 \\
\hline $\mathrm{r}_{0}$ & $0,02[\mathrm{~m}]$ & $\mathrm{r}_{0}$ & $0,02[\mathrm{~m}]$ \\
\hline $\mathrm{r}_{\mathrm{i}}$ & $0,0326[\mathrm{~m}]$ & $r_{i}$ & $0,0326[\mathrm{~m}]$ \\
\hline $\mathrm{k}_{\mathrm{p}}$ & {$\left[0,4 \mathrm{~W} \cdot(\mathrm{m} \cdot \mathrm{K})^{-1}\right]$} & $\mathrm{k}_{\mathrm{p}}$ & $0,4\left[\mathrm{~W} \cdot(\mathrm{m} \cdot \mathrm{K})^{-1}\right]$ \\
\hline $\mathrm{T}_{\mathrm{g} \cdot \min }{ }^{\mathrm{b}}$ & $-5\left[{ }^{\circ} \mathrm{C}\right]$ & $\mathrm{T}_{\text {g.max }} \mathrm{c}$ & $43\left[{ }^{\circ} \mathrm{C}\right]$ \\
\hline $\mathrm{T}_{\mathrm{f}, \min }$ & $1\left[{ }^{\circ} \mathrm{C}\right][7]$ & $\mathrm{T}_{\mathrm{f}, \max }$ & $36\left[{ }^{\circ} \mathrm{C}\right][7]$ \\
\hline RunFunction $_{h}{ }^{d}$ & 0,34 & RunFunction $_{\mathrm{c}}{ }^{\mathrm{d}}$ & 0,34 \\
\hline
\end{tabular}

\section{f. Economic Assessment}

A simplified cost-revenue analysis considered plant costs, operative costs and dismantling. Evaluations were performed before taxes, by analyzing cash flows only and by considering total costs and revenues at the end of each year. To compare flows occurred in different years, these were discounted to year 0 through a discount rate. Both the absence of public incentives and the application of the best incentive regime applicable to the specific case were considered. Two economic parameters were assessed: Net Present Value (NPV) and Pay Back Time (PBT). Values assumed are: energy cost $0,18[€ / \mathrm{kWh}]$; price of the energy introduced into the grid $0,12[€ / \mathrm{kWh}]$; discount rate 2 [\%]. Most of the values applied in the economic analysis of PV and geothermal systems were taken from market investigations.

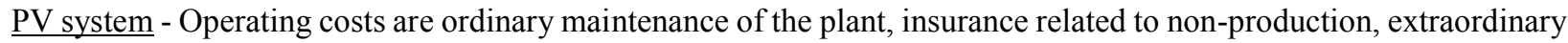
maintenance at the 10th year (replacement of inverters), disposal at the end of life, at the 20th year.

Electric storage - A $100 \mathrm{kWh}$-capacity storage system based on batteries was considered. Costs taken into account are extraordinary maintenance (batteries replacement after 10 years) and dismantling at the end of life (20 years). Values assumed in this part of the economic analysis were obtained through preliminary evaluations.

Water-water heat pump coupled with a vertical geothermal probe - Investment costs are those of the geothermal probe, of the pumping system and of the new heat pump. Operative costs are related to maintenance and to electricity required by the primary circuit to circulate the liquid mixture. If the probe is embedded into the ground, installation costs are those of drilling. If the probe is installed into a groundwater well, only costs of the intermediate heat exchanger placed between the probe and the heat pump were considered.

\subsection{Results}

Territorial framework of the pilot area - Recent sandy and alluvial deposits characterize the area. Where water was stored, aquifers are small in size and storage capacity. The pilot site falls within the main thermal area "Southwestern Sardinia" [13]. Temperatures at $100[\mathrm{~m}]$ depth range from $21\left[{ }^{\circ} \mathrm{C}\right]$ to $30\left[{ }^{\circ} \mathrm{C}\right]$; heat flux is less than $75\left[\mathrm{~mW} \cdot \mathrm{m}^{-2}\right]$, roughly close to $60\left[\mathrm{~mW} \cdot \mathrm{m}^{-2}\right][14]$.

Energetic Analysis

a. Electricity consumption

Monthly and annual consumption values derived from electricity bills are reported in Fig. 1. 


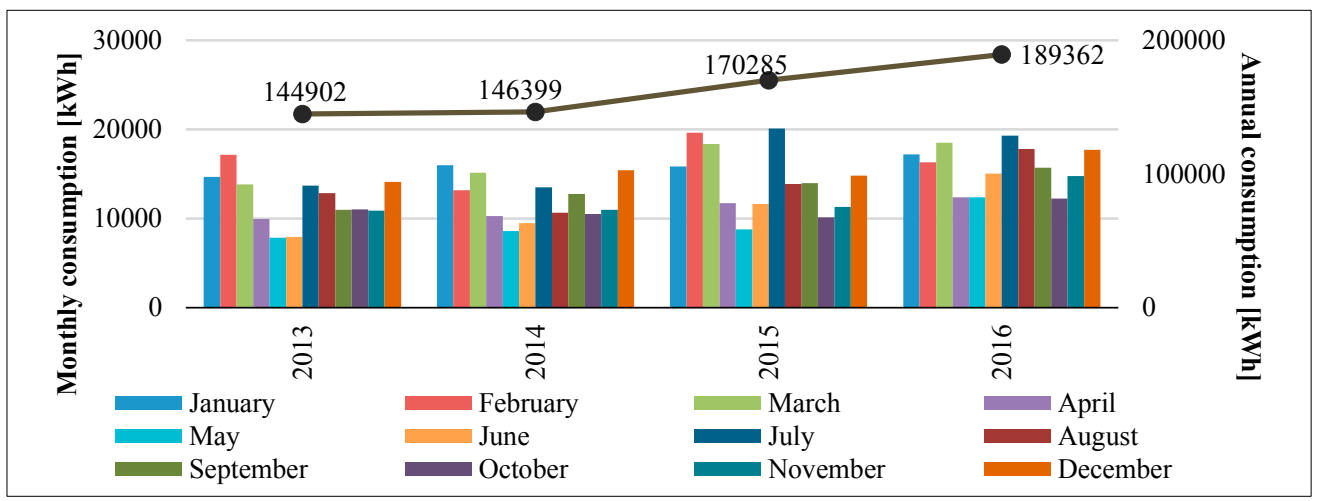

Fig. 1. Monthly consumption and total electricity consumption per year. Period 2013-2016.

Energy consumed increased. The energy consumption increase in the cold/warm season is due to heating/cooling. Annual consumption profile on an hourly basis, derived from quarterly-hour data of bills, is reported in Fig. 2. Values detected on the electric cabin were considerably higher than bills, due to a malfunction of the monitoring system. Workshop consumption varies between 3000 and $9000[\mathrm{kWh}]$ per month.

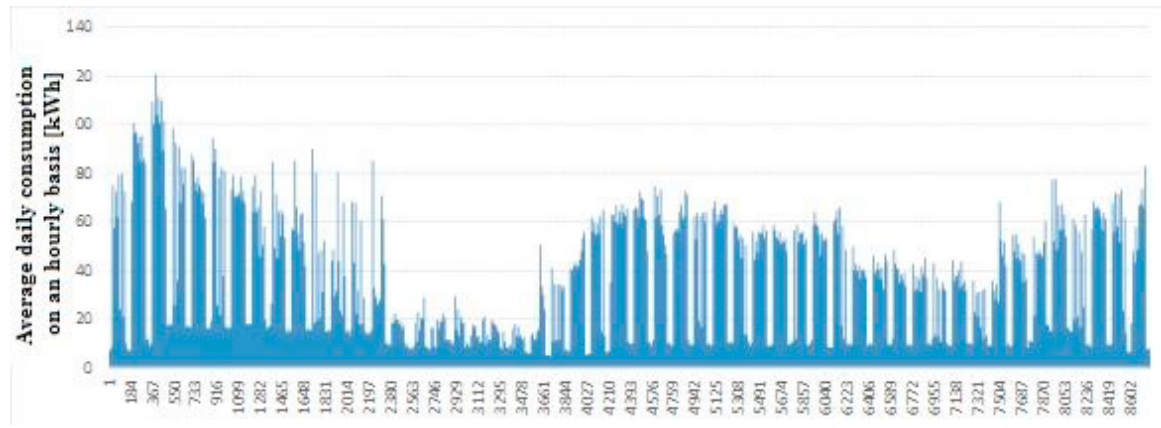

Fig. 2. Daily consumption on an hourly basis. Annual distribution.

b. Energy performance evaluations

Indicators of the section "Offices" and benchmarks are reported in Tab. 3.

\begin{tabular}{|c|c|c|c|c|}
\hline \multirow[t]{2}{*}{ Section } & \multicolumn{2}{|c|}{$\begin{array}{l}\text { Indicator per unit area } \\
{\left[\mathrm{kWh} \cdot \mathrm{m}^{-2}\right]}\end{array}$} & \multicolumn{2}{|c|}{$\begin{array}{l}\text { Indicator per employee } \\
{\left[\mathrm{kWh} \cdot \text { person }^{-1}\right]}\end{array}$} \\
\hline & $\begin{array}{l}\text { Pilot Building } \\
21,8\end{array}$ & $\begin{array}{l}\text { Benchmark } \\
139\end{array}$ & $\begin{array}{l}\text { Pilot Building } \\
758\end{array}$ & $\begin{array}{l}\text { Benchmark } \\
3700\end{array}$ \\
\hline
\end{tabular}

c. Hourly production of the PV plant

The hourly production profile of the PV plant is reported in Fig. 3. 


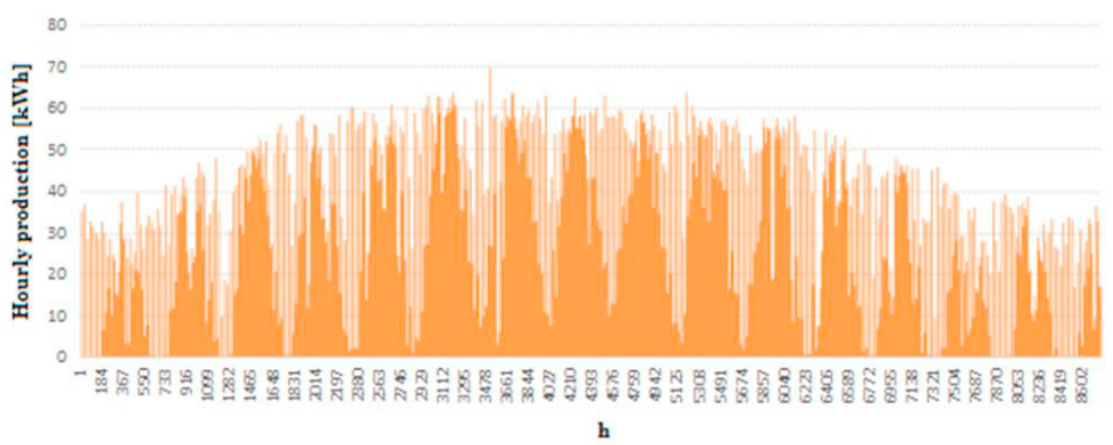

Fig. 3. Hourly production of the PV plant on an annual basis.

\section{d. Electric storage scenario}

By comparing Fig. 2 and Fig. 3, a not perfect overlapping of trends can be observed. The annual building consumption is 191604 [kWh], while the PV production is of 115777 [kWh]. The PV system cannot meet the energy demand, especially in cold months, but it will overproduce when the AC is not necessary. The PV gross coverage of electricity consumption is $60.4 \%$. Considering contemporaneity of energy consumption and PV production, the coverage without storage decreases to $40.8 \%$. The percentage of PV energy self-consumed is $67.5 \%$. Without introduction into the grid, the electric storage system should have a capacity of 11302 [kWh], which is not economically viable. Thus, a storage solution of $100 \mathrm{kWh}$-capacity was chosen. It will lead to an increase of the energy self-consumed. The resulting net coverage will be $49.0 \%$, with a self-consumption percentage of $81.0 \%$.

e. Heat pump coupled with a low-enthalpy geothermal probe for heating and cooling

The most important characteristics of the selected water-water heat pump are:

- Heating (reference values: outlet temperature of the evaporator of $5\left[{ }^{\circ} \mathrm{C}\right]$, that of the condenser of $45\left[{ }^{\circ} \mathrm{C}\right]$ ): nominal power (heating) 179,02 [kW]; COP 4,43; absorbed power 40,04 [kW]; water flow rate $24.540\left[1 \cdot \mathrm{h}^{-1}\right]^{\mathrm{a}}$.

- Cooling (reference values: outlet temperature of the evaporator of $7\left[{ }^{\circ} \mathrm{C}\right]$, that of the condenser of $35\left[{ }^{\circ} \mathrm{C}\right]$ ): nominal power (cooling) 169,34 [kW]; absorbed power 33,5 [kW]; Energy Efficiency Ratio (E.E.R.) 5,05; water flow rate $29.130\left[1 \cdot h^{-1}\right]^{\text {a }}$.

The total length of the probes field in cooling conditions is 2585 [m]; that in heating conditions is 2714 [m]. Thus, the probes field is made of 7 double-U probes. Each probe's length is 97 [m].

${ }^{a}$ Official values provided by the producer

\section{f. Economic assessment}

PV system and electric storage - The PV plant's NPV is $42000 €$. Its PBT is between 13 and 14 years. The storage system's NPV is always negative in the 20 -yr window.

Water-water heat pump coupled with a vertical geothermal probe - The NPV of the geothermal probe embedded into the ground is negative because of high drilling costs. The NPV of the geothermal probe installed into a groundwater well is positive (without incentive is $33700 €$; with the $65 \%$ of incentive is $55000 €$ ). Its PBT is 9 years without incentive and 6 years with the application of the incentive.

\section{Conclusions}

In this work, a low-enthalpy geothermal system for air conditioning in the Mediterranean climate was preliminarily assessed, by using an Italian research center as a pilot building. Specifically, preliminary technical and economic evaluations were carried out, to define the model configuration and its maximum size (due to the overestimation of 
the probes field generated by the IGSHPA method). The model will be made of a PV system to meet the electricity demand, an electric storage of energy surplus and a low-enthalpy geothermal system for AC. This one will consist in a water-water heat pump coupled with a vertical geothermal probe embedded into the ground or installed in an already existing groundwater well. The energetic analysis performed using electricity consumption data sets allowed us to define the energy demand during the year, especially for AC. By applying the IGSHPA method, the probes field has a total length of $2715[\mathrm{~m}]$, corresponding to 7 double U-type probes, each one 97 meters long. The PV plant is economically viable, but not the electric storage. The AC system using the low-enthalpy geothermal energy is economically viable only in the case of using the existing groundwater well. A water flow test should be carried out on the already existing well (currently, it is not equipped with a water pump), to determine the availability of water required by the heat pump. Also, a hydrogeological assessment of the study area should be provided, to define the potential impacts of the groundwater characteristics and flow direction on the probes sizing, through a more complex and comprehensive numerical model. Thus, the future development of these preliminary evaluations will consist in the above-mentioned surveys on the groundwater system, in a Ground Response Test, to better define the effective thermal conductivity, resulting in a more in-depth sizing of the probes field, to be compared to the preliminary results of the IGSHPA method. In addition, comparisons will be made between the results of a numerical model and those provided by the analytical method IGSHPA. In this study, the solution of the probe embedded into the ground is not economically affordable because drilling costs affect the return on the investment. A system analysis using the Finite Element Method (FEM) will allow us to evaluate the evolution of the soil temperatures distribution around the probe [15].

\section{Acknowledgements}

Gratefully acknowledges Sotacarbo S.p.A. for the financial support.

\section{References}

[1] Fufa, Selamawit Mamo, Schlanbusch, Reidun Dahl, Sørnes, Kari, Inman, Marianne, and Andresen, Inger. (2016) A Norwegian ZEB Definition Guideline, ZEB report 29. Trondheim: Sintef Academic Press, (2016).

[2] Sailer, Eleonora, Taborda, David M.G., Keirstead, James. (2015). "Assessment of Design Procedures for Vertical Borehole Heat Exchangers." Proceedings of the Fortieth Workshop on Geothermal Reservoir Engineering Stanford University, Stanford, California, January 26-28, (2015)

[3] UNI 11466:2012. Sistemi geotermici a pompa di calore -Requisiti per il dimensionamento e la progettazione.

[4] Kim, E.J., Roux, J.J., Rusaouen, G., Kuznik, F. (2010) "Numerical modeling of geothermal vertical heat exchangers for the short time analysis using the state model size reduction technique". Applied Thermal Engineering, 30 (6-7), 706-714.

[5] Bezyan, B., Porkhial, S., Aboui Mehrizi, A. (2015) 3-D simulation of heat transfer rate in geothermal pile-foundation heat exchangers with spiral pipe configuration. Applied Thermal Engineering, 87, 655-668.

[6] Biglarian, Hassan, Abbaspour Madjid, Saidi, Mohamad HHassan. (2017) "A numerical model for transient simulation of borehole heat exchangers." Renewable Energy, 104, 224-237.

[7] Santini, Ezio, Elia, Stefano, Fasano, Gaetano. (2009) “Caratterizzazione dei consumi energetici nazionali delle strutture ad uso ufficio.” Ricerca Sistema Elettrico, Report RSE/2009/121.

[8] VDI. (2010) Thermal use of the underground - Fundamentals, approvals, environmental aspects, Corrigendum concerning guideline VDI 4640 Blatt 1:2010-06.

[9] ASHRAE. (2007) ASHRAE handbook - HVAC applications. Chapter 32. ASHRAE, Atlanta, GA

[10] IGSHPA. (1991) “Design and installation standards.” International Ground Source Heat Pump Association, Stillwater, Oklahoma

[11] UNI/TS 11300-1. (2008) Prestazioni energetiche degli edifici - Parte 1: Determinazione del fabbisogno di energia termica dell'edificio per la climatizzazione estiva ed invernale.

[12] Ruan, Wei, and Horton, William Travis. (2010). "Literature Review on the calculation of Vertical Ground Heat Exchangers for Geothermal Heat Pump Systems." Proceedings of the International High Performance Buildings Conference, Purdue, July 12-15, (2010).

[13] National Research Council. (1982) Ricerche geotermiche in Sardegna con particolare riferimento al graben del Campidano: relazione finale sul tema di ricerca "Studi geologici, idrogeologici e geofisici finalizzati alla ricerca di fluidi caldi nel sottosuolo, Pisa

[14] Caboi, R., Fanfani, L., Pecorini, G.; Fancelli, R., Squarci, P., Taffi, L. (1988) "Inventario delle risorse geotermiche della Sardegna." In Inventario delle risorse geotermali nazionali, Ministero Sviluppo Economico-Direzione Generale per le risorse minerarie ed energetiche

[15] Orrù, Pier Francesco, and Pilloni, Maria Teresa. (2007) "Progettazione di un Impianto di Climatizzazione Alimentato tramite Pompa di Calore. Confronto Tecnico-Economico fra Pompa di Calore Geotermica e Tradizionale." Proceedings of the XXXIV National Congress ANIMP, (2007). 